\title{
BMJ Open General practitioners' justifications for therapeutic inertia in cardiovascular prevention: an empirically grounded typology
}

Jean-Pierre Lebeau, ${ }^{1}$ Jean-Sébastien Cadwallader, ${ }^{2}$ Hélène Vaillant-Roussel, ${ }^{3}$ Denis Pouchain, ${ }^{2}$ Virginie Yaouanc, ${ }^{4}$ Isabelle Aubin-Auger, ${ }^{5}$ Alain Mercier, ${ }^{6}$ Emmanuel Rusch, ${ }^{7}$ Roy Remmen, ${ }^{8}$ Etienne Vermeire, ${ }^{8}$ Kristin Hendrickx ${ }^{8}$

To cite: Lebeau J-P, Cadwallader J-S, VaillantRoussel $\mathrm{H}$, et al. General practitioners' justifications for therapeutic inertia in cardiovascular prevention: an empirically grounded typology. BMJ Open 2016;6: e010639. doi:10.1136/ bmjopen-2015-010639

- Prepublication history and additional material is available. To view please visit the journal (http://dx.doi.org/ 10.1136/bmjopen-2015010639).

Received 25 November 2015 Revised 9 March 2016 Accepted 24 March 2016

CrossMark

For numbered affiliations see end of article.

Correspondence to Dr Jean-Pierre Lebeau; jean-pierre.lebeau@ univ-tours.fr

\section{ABSTRACT}

Objective: To construct a typology of general practitioners' (GPs) responses regarding their justification of therapeutic inertia in cardiovascular primary prevention for high-risk patients with hypertension.

Design: Empirically grounded construction of typology. Types were defined by attributes derived from the qualitative analysis of GPs' reported reasons for inaction.

Participants: 256 GPs randomised in the intervention group of a cluster randomised controlled trial.

Setting: GPs members of 23 French Regional Colleges of Teachers in General Practice, included in the EffectS of a multifaceted intervention on CArdiovascular risk factors in high-risk hyPErtensive patients (ESCAPE) trial.

Data collection and analysis: The database consisted of 2638 written responses given by the GPS to an open-ended question asking for the reasons why drug treatment was not changed as suggested by the national guidelines. All answers were coded using constant comparison analysis. A matrix analysis of codes per GP allowed the construction of a response typology, where types were defined by codes as attributes. Initial coding and definition of types were performed independently by two teams.

Results: Initial coding resulted in a list of 69 codes in the final codebook, representing 4764 coded references in the question responses. A typology including seven types was constructed. $100 \mathrm{GPs}$ were allocated to one and only one of these types, while 25 GPs did not provide enough data to allow classification. Types (numbers of GPs allocated) were: 'optimists' (28), 'negotiators' (20), 'checkers' (15), 'contextualisers' (13), 'cautious' (11), 'rounders' (8) and 'scientists' (5). For the $36 \mathrm{GPs}$ that provided 50 or more coded references, analysis of the code evolution over time and across patients showed a consistent belonging to the initial type for any given GP.

Conclusion: This typology could provide GPs with some insight into their general ways of considering changes in the treatment/management of cardiovascular risk factors and guide design of specific

\section{Strengths and limitations of this study}

- The typology was constructed from the data gathered during the study, without any preestablished framework, and therefore reflects the actual way general practitioners (GPs) rationalise their reasons for inaction.

- The initial coding and the physician types initially described separately and blindly by the two coding teams were remarkably consistent.

- For the GPs who provided enough data to allow such an analysis, the types of responses given were consistent over time and across patients.

- Social desirability bias may have influenced the content of the data; in writing down reasons for inaction, a physician would consider the acceptability of the response.

- The GPs included may not represent the general GP population, because they were specifically trained in treating cardiovascular risk factors for the Evaluation Study of Congestive Heart Failure and Pulmonary Artery Catheterization Effectiveness (ESCAPE) trial intervention group and were involved to various extent in general practice teaching.

physician-centred interventions to reduce inappropriate inaction.

Trial registration number: NCT00348855.

\section{INTRODUCTION}

Guidelines for the primary prevention of cardiovascular events in patients with hypertension have been widely disseminated. ${ }^{1-4}$ They cover blood pressure (BP) targets that should be achieved and other risk-reducing strategies regarding low-density lipoprotein (LDL) cholesterol and smoking cessation. For patients with hypertension with type 2 diabetes, specific BP targets are recommended, along with 
haemoglobin Alc (HbAlc) targets and low-dose acetylsalicylic acid treatment in specific cases. ${ }^{1}$ These guidelines and targets rely on an extensive body of evidence from a substantial number of large randomised controlled trials. $^{5-7}$

Nevertheless, most patients with hypertension do not achieve control according to the recommended targets. ${ }^{8}$ In the UK, $30 \%$ of people aged between 20 and 79 years are hypertensive, but among them only $65 \%$ are aware of their condition. Of these, $51 \%$ are treated and $27 \%$ are controlled. ${ }^{9}$ These figures are even worse in France, where $31 \%$ of people aged $18-74$ years are hypertensive, $52 \%$ are aware, $42 \%$ treated and $21 \%$ optimally controlled. ${ }^{10}$ Evidence from the USA and Canada also shows considerable room for improvement. ${ }^{9}$ Overall, in Europe and North America, more than half of the patients with hypertension are uncontrolled. ${ }^{11}{ }^{12}$ Furthermore, when multiple risk factors are active in one patient, control of each risk factor becomes even more suboptimal. $^{12} 13$

Various causes may explain this gap between proposed targets and actual clinical outcomes. While patients' lack of adherence remains a prominent factor, ${ }^{14}$ the responsibility of the healthcare professional has been more recently brought to light. ${ }^{15}$ Among the various reasons that often keep adherence to guidelines low, therapeutic inertia (TI), or the failure of healthcare providers to initiate or increase treatment when the therapeutic targets are not met, is now regarded as a major impediment to reach individual and public therapeutic goals regarding cardiovascular risk factors. ${ }^{11} 1516$ The existence of TI in the management of modifiable cardiovascular risk factors has been shown. ${ }^{16-18}$ For uncontrolled BP in patients with treated hypertension in European countries, TI occurs in up to $85 \%$ of consultations. ${ }^{11}$

A number of explanations have been proposed to understand this phenomenon. The subjective overestimation by the practitioner of the care provided, a lack of familiarity with the guidelines or organisational issues have been shown to lead to TI. ${ }^{17}{ }^{18}$ Various hypotheses regarding the intimate mechanisms underlying these behaviours have also been proposed, ${ }^{15} 1920$ but very few qualitative studies have explored these in depth. ${ }^{21-23}$ Studies were based on either nominal or focus groups, but did not specifically explore what happens during consultations with individual patients.

Decision-making is an important issue in psychological research, and the use of typologies has proven effective to better understand vocational choices ${ }^{24}$ or to characterise the effects of cultural differences. ${ }^{25}$ Regarding healthcare, typical patterns of dealing with clinical issues and typologies in decision-making have been brought to light in various situations. ${ }^{26}{ }^{27}$ Decision-making is also crucial and very specific in cardiovascular primary prevention, where the physician should prescribe drugs and rules to an asymptomatic patient, expecting a hypothetical benefit that will remain unseen. A typology of general practitioners' (GPs) decision-making in cardiovascular primary prevention in actual clinical practice has not been proposed yet.

In this qualitative study, the objective was to construct a typology of GPs' responses regarding their justification of TI in cardiovascular primary prevention. We explored the reasons put forward by GPs for not optimising a treatment when indicated, that is, to explain their TI, and then looked for possible patterns of responses that could be clustered into types.

\section{METHODS}

\section{Qualitative approach}

We performed an empirically grounded construction of typology. ${ }^{28-30}$ A typology is made up of a number of types. Each type is constructed and defined by a combination of attributes. These attributes are codes that resulted from the qualitative analysis of the responses collected from the GPs included. The typology described the reasons given for not initiating or reinforcing a preventive cardiovascular drug treatment when indicated. Although the aim was to construct a typology, there was no initial framework, and all types were inductively derived from the data.

In the process of constructing the typology, the combination of two rules was followed:

- The GPs within one type had to be as similar as possible, and the differences between the types as strong as possible. ${ }^{28}$

- Each GP had to belong to one and only one type. $^{28} 30$

\section{Population}

For this study, qualitative data of the EffectS of a multifaceted intervention on CArdiovascular risk factors in high-risk hyPErtensive patients (ESCAPE) trial were analysed. The quantitative part of ESCAPE was a cluster randomised controlled trial conducted in general practice settings in France. It aimed at determining whether a multifaceted intervention focused on GPs could increase the proportion of high-risk patients with hypertension in primary prevention who achieved their recommended therapeutic targets. The results have been published elsewhere. $^{31}$

The GPs involved in this qualitative study were all in the intervention group of the ESCAPE trial. ${ }^{31}$ As the intervention of the trial was at the GPs level, they all attended a 1 day training seminar about therapeutic targets and strategies recommended by the French national guidelines. ${ }^{1}{ }^{2}$ Four trained university GP lecturers delivered the standardised training seminars, using the same teaching kit. A validated electronic BP measurement device (Spengler TB101, Spengler SAS, Antony, France) was provided to the GPs to improve the accuracy of BP measurements. A six-page leaflet that summarised therapeutic targets and strategies recommended in the guidelines was also provided, and the GPs were asked to keep it on their office desk. 
A total of 126 GPs formed the intervention group of the ESCAPE trial and recruited at least one patient; 125 provided qualitative data. On average, GPs were aged $51(\mathrm{SD}=5.4)$ years, with a male/female ratio of $80 / 20$ (table 1).

The patients recruited were aged 40-75 years, treated for hypertension for at least 6 months, in primary prevention, with at least two other cardiovascular risk factors (age/gender, family history, type 2 diabetes, high LDL cholesterol, left ventricular hypertrophy or smoking). A total of 905 patients were recruited (7.2 per GP; range 1-18). On average, they were aged 62 (SD 7.8) years and had been treated for hypertension for an average of 10.9 years (SD 8.1). A total of $71 \%$ had more than two other associated cardiovascular risk factors and $57 \%$ had type 2 diabetes (table 2). Each patient was seen five times during this trial.

\section{Data collection}

As planned in the ESCAPE protocol, at the end of each of the five consultations per patient dedicated to cardiovascular prevention, GPs in the intervention group were asked to write in the case report form the answer to the following open-ended question:

If the therapeutic targets recommended in the guidelines for this patient were not reached (blood pressure, LDL-cholesterol, HbAlc, and low-dose aspirin for diabetic patients) and you did not change the medication, could you tell us why?

This led to the collection of up to five responses per patient.

\section{Coding}

All the responses were entered into a database and coded using a constant comparison process without predetermined categories. This generated an initial list of codes. The initial coding was performed independently by two teams of researchers (JPL/VY and IAA/AM)

\begin{tabular}{lll}
\multicolumn{2}{l}{ Table 1 Characteristics of the GPs } \\
\hline Characteristics & N & Per cent \\
\hline Overall & 125 & 100 \\
Gender & & \\
$\quad$ Male (\%) & 100 & 80 \\
$\quad$ Female (\%) & 25 & 20 \\
Mean age (SE) & $50.2( \pm 5.4)$ & \\
Mean years of practice (SE) & $21.0( \pm 6.5)$ & \\
Area of practice & & \\
$\quad$ Urban & 67 & 53.6 \\
$\quad$ Semirural & 40 & 32.0 \\
$\quad$ Rural & 18 & 14.4 \\
Conditions of practice & & \\
$\quad$ Joint & 91 & 72.8 \\
$\quad$ Single & 34 & 27.2 \\
\hline GPs, general practitioners. & &
\end{tabular}

Table 2 Characteristics of the patients

\begin{tabular}{|c|c|}
\hline Characteristic & $\begin{array}{l}N=905 \\
N(\%)\end{array}$ \\
\hline Male, $\mathrm{n}(\%)$ & $575(63.5)$ \\
\hline Mean age, years (SD) & $62.1(7.9)$ \\
\hline Body mass index, $\mathrm{kg} / \mathrm{m}^{2}$ (SD) & $30.7(5.2)$ \\
\hline Mean systolic blood pressure, $\mathrm{mm} \mathrm{Hg}(\mathrm{SD})^{*}$ & $145.9(15.3)$ \\
\hline Mean diastolic blood pressure, $\mathrm{mm} \mathrm{Hg}(\mathrm{SD})^{*}$ & $83.7(11.7)$ \\
\hline LDL, mmol/L (SD) & $3.19(1.02)$ \\
\hline $\begin{array}{l}\text { MDRD-estimated glomerular filtration rate, } \\
\mathrm{mL} / \mathrm{min}(\mathrm{SD})\end{array}$ & $79.6(19.6)$ \\
\hline Left ventricular hypertrophy, n (\%) & $150(16.6)$ \\
\hline $\begin{array}{l}\text { Family history of early cardiovascular event, } \\
\mathrm{n}(\%)\end{array}$ & $225(24.9)$ \\
\hline Albuminuria $\geq 20$ mg/L, n (\%) & $186(22.3)$ \\
\hline $\begin{array}{l}\text { Mean years since diagnosis of hypertension } \\
\text { (SD) }\end{array}$ & $10.5(7.8)$ \\
\hline \multicolumn{2}{|l|}{ Smoker status } \\
\hline Current n (\%) & $193(21.3)$ \\
\hline ooker <3 years $n(\%)$ & $72(8.0)$ \\
\hline noker n (\%) & $640(70.7)$ \\
\hline Number of antihypertensive drugs, $n$ (SD) & $2.16(1.04)$ \\
\hline Type 2 diabetes, n (\%) & $527(58.2)$ \\
\hline $\begin{array}{l}\text { Mean years since diagnosis of type } 2 \\
\text { diabetes (SD) }\end{array}$ & $6.9(6.1)$ \\
\hline $\mathrm{HbA1c}, \%$ (SD) & $7.0(1.1)$ \\
\hline \multicolumn{2}{|l|}{ Cardiovascular risk factors, $\mathrm{n}(\%)$} \\
\hline Men $>50$ or women $>60$ years & $779(86.1)$ \\
\hline Current smoker or past smoker $<3$ years & 265 (29.3) \\
\hline $\mathrm{LDL} \geq 4.14 \mathrm{mmol} / \mathrm{L}$ or treatment & $692(76.5)$ \\
\hline $\mathrm{HDL} \leq 1.04 \mathrm{mmol} / \mathrm{L}$ & $189(20.9)$ \\
\hline \multicolumn{2}{|l|}{ Number of cardiovascular risk factors, $\mathrm{n}(\%)$} \\
\hline$\leq 2$ & $259(28.6)$ \\
\hline$\overline{3}$ & $319(35.2)$ \\
\hline 4 & $222(24.5)$ \\
\hline$\geq 5$ & $105(11.6)$ \\
\hline $\begin{array}{l}\text { Mean } 10 \text {-year Framingham-Anderson risk } \\
\text { score (\%) }\end{array}$ & 17.5 \\
\hline
\end{tabular}

using a qualitative analysis software package (NVivo 9.2, QSR International Pty Ltd, Doncaster, Australia; 2011). The two lists were then combined into one final codebook. Discrepancies were resolved by discussion, and remaining disagreements went to arbitration with a fifth researcher (JSC).

\section{Attributes and types}

A matrix was constructed, where codes were the columns and GPs were the rows. The number in each cell was the number of occurrences of the code found in the responses of each GP. In order to have as much data as possible in a manageable size, a submatrix of the 10 GPs who provided the greatest number of codes was first analysed to characterise GP types and start constructing the typologies. From this submatrix, researchers defined relevant codes as major or minor attributes to construct 
and define types. The decision to use a given code as a major or minor attribute of a type was taken independently by the two teams of researchers (JPL/VY and $\mathrm{IAA} / \mathrm{AM})$, and then discussed with the arbitration of a third team (JSC and DP) for a final consensus. The types thus defined were then applied to 30 other randomly allocated GPs (10 for each of the three teams) to check for other emerging types and characterise them.

\section{Typology}

The types were applied to the whole matrix, and every GP that provided sufficient data was allocated to one type.

Finally, we checked for consistency per GP of belonging to one type over time and from one patient to another. In order to have sufficient data for this, we selected and checked the GPs who provided more than 50 coded references.

\section{Registration}

The Institutional Review Board of Versailles approved the ESCAPE trial, which included this qualitative study. The ESCAPE trial was registered with ClinicalTrials.gov, number NCT00348855.

\section{RESULTS}

\section{Data collection}

The 125 GPs performed 4295 visits for the ESCAPE trial for 905 patients and gave 2638 answers (from 1 to 59) to the open-ended question. Responses were transcribed verbatim to form the database. Qualitative analysis of the database provided the results.

\section{Coding}

Initial coding resulted in a list of 69 codes in the final codebook, representing 4764 coded references from the responses (table 3 ).

\section{Attributes and types}

The matrix was constructed (see online supplementary additional file 1), and the submatrix of the 10 GPs who provided the largest numbers of codes (from 85 to 173) was extracted to define each type and its attributes. Both teams of researchers determined the same five types, with slight differences in the major and minor attributes that characterised these types. Discussion and arbitration with the third team resolved the final definition of six types ('procrastinators' was split into 'checkers' and 'negotiators'). Belonging to one type depended on fulfilling at least one of the two or three major attributes, and at least three of the minor attributes defining that type (table 4).

Application of the templates to the subsequent 30 randomly allocated GPs lead to the emergence of a seventh type (scientists).
Table 3 Final codebook

Codes

Number of references

Exercise and/or diet in progress

203

Lifestyle changes instructions first 129

Recent changes

122

Patient's promise

25

Expectations

20

Just wait and see

5

Scheduled re-evaluation $\quad 277$

Referral

121

Scheduled change $\quad 38$

Other specialist's advice 63

GP's opinion $\quad 45$

Selected result $\quad 37$

Partial modification $\quad 36$

Omission 33

Minor modification $\quad 24$

Other scientific reasons 13

Doubt on treatment effectiveness $\quad 7$

No time

Lifestyle rules $\quad 588$

Weight loss $\quad 53$

Dietician 34

Alternate treatment $\quad 11$

Adverse effect $\quad 196$

Long prescription/polypharmacy $\quad 85$

Precautions of use $\quad 69$

Insulin 48

Maximal treatment $\quad 36$

Adherence to non-drug treatment 298

Adherence to drug treatment $\quad 89$

Treatment interrupted 40

Patient's preferences $\quad 123$

Psychological profile $\quad 110$

Alcohol $\quad 57$

Socioprofessional context 43

Familial context $\quad 29$

Stress $\quad 27$

Hopeless $\quad 10$

Professional risk 6

Age 5

Other intercurrent disease $\quad 158$

Depressive disorder $\quad 24$

$\begin{array}{ll}\text { Sleep apnoea } & 7\end{array}$

Drug-related medical intercurrent event $\quad 30$

Non-medical intercurrent event $\quad 119$

Organisational issue $\quad 101$

Other medical priority $\quad 46$

Sleep issues 6

HBPM unknown procedure $\quad 161$

HBPM incorrect procedure $\quad 45$

HBPM correct procedure $\quad 26$

Recent cardio check-up $\quad 92$

ABPM 23

Echocardiography $\quad 2$

Borderline results $\quad 136$

Unusual results $\quad 123$

'Not so bad' results 65

Preference for manual device $\quad 71$

Continued 
Table 3 Continued

\begin{tabular}{lc}
\hline Codes & $\begin{array}{c}\text { Number of } \\
\text { references }\end{array}$ \\
\hline Inadequate arm cuff & 38 \\
Unreliable measurement device & 19 \\
Preference for another electronic device & 13 \\
Missing results & 44 \\
White coat effect & 36 \\
Circumstances of measurement & 33 \\
Not estimable LDL cholesterol & 15 \\
Preference for self-measured glycaemia & 12 \\
Negotiation & 83 \\
Limitation of instructions & 39 \\
Hierarchical organisation & 29 \\
Confidence & 12 \\
69 codes & 4764 \\
\hline The number of references for a given code represents the number \\
of sections of the initial verbatim allocated to that particular code. \\
ABPM, ambulatory blood pressure measurement; GP, general \\
practitioner; HBPM, home blood pressure measurement; LDL, \\
low-density lipoprotein.
\end{tabular}

\section{Typology}

Applying the attributes to the whole database allowed the classification to one of the seven response types for 100 of the 125 GPs. The 25 remaining did not have enough data to allow a classification using attributes (figure 1). For the 100 GPs allocated to a type, the mean number of patient was 8.0 (range 2-18).

The 'optimists' was the largest group (28 GPs). Great expectations related to the patient's recent or expected lifestyle changes were their central characteristics: 'Repeating the lifestyle recommendations should be enough to reach the HbA1c target'. Three GPs had a 'negotiator' tendency, but the negotiations were mostly focused on lifestyle too: 'We insisted again on diet and exercise'. Follow-up visits for re-evaluations were often scheduled.

Twenty GPs were classified as 'negotiators'. Difficulties in negotiating the treatment (including lifestyle changes) with the patient were the main argument for not changing it: 'No aspirin: says he won't take it anyway...'. 'Partial modification' was a frequent way to overcome these difficulties: 'He finally accepted the statin, so I did not insist on aspirin'. Two GPs in this group had a profile close to the 'optimists': 'So I finally asked for lifestyle modification, which, after all, might do...'.

Fifteen GPs were 'checkers'. TI was justified by results that were either close to the targets or questionable with regard to the usual results: 'BP usually not as high. Will check in 6 months and ask for a home measurement if still as high'.

'Contextualisers' accounted for 13 of the GPs. Abnormalities in measurement results were attributed to either associated events (including the circumstances of measurement) or socioprofessional context: 'High BP, but drove a long way to the practice, and waited a long time in the overheated waiting room'; 'Is in the middle of a political campaign'. Intercurrent medical events could be seen either as a cause for bad results or as priorities that justified postponing any other medical intervention: 'Very anxious about the surgery (and so am I). I didn't even mention the high $B P$ '.

The 'cautious' type included 11 GPs. Fear of adverse effects was their main characteristic. Possible gastric adverse effect of aspirin, muscular adverse effect of statins and orthostatic hypotension were the most frequently invoked reasons: 'No aspirin because of gastrointestinal history'; 'Statins might not be well tolerated'. Of note, one GP in this group reported that all of his six patients with diabetes were 'allergic to aspirin'.

Eight GPs were 'rounders'. They had a tendency to consider the results as close enough to the targets to justify inaction: 'BP close to target. HbA1c is getting better. LDL-c is very close to target'.

The 'scientists' included five GPs. Their reasons for inaction were based on evidence, which could be new studies, new guidelines or specialists' advices: 'The cardiologist he met in January said: no aspirin'. Three GPs defended their disagreement with the guidelines by providing the contradictory results of more recent publications: 'I disagree with the guidelines regarding aspirin: read the recent New England article!. While the attributes for this type were few, these GPs were quite consistent in showing these attributes only.

No GP fulfilled the attributes to belong to two different types. However, 27 had a tendency to relate to another type (one major attribute, and one or two minor). Table 5 summarises the inter-relations between the types.

For the 36 GPs that provided 50 or more coded references, analysis of the code evolution over time and from one patient to another showed consistency with their initial type for any given GP.

\section{DISCUSSION}

\section{Main findings}

A typology including seven types was constructed from the qualitative analysis of GPs' reported reasons for not initiating or reinforcing cardiovascular primary prevention drug treatment. For the GPs who provided enough data to allow such an analysis, the types of responses given were consistent over time, and across patients.

\section{Detailed findings and comparison with existing literature}

Defining a typology regarding the reasons provided for not initiating or increasing the treatment of a cardiovascular risk factor when indicated has not been done previously. The survey study of Oliveria $e t a l^{32}$ did ask the physician the reasons of the decision for a given patient, but it was not conducted in a framework where the physician was specifically urged to give guideline-based care. While our results cannot be confronted with previous results of the exact same nature, the various factors and behaviours involved in the inaction process have all been described before.

Reviewing the whole database for a first impression, the overwhelming confidence in lifestyle counselling is 
Table 4 Attributes for the seven types

\begin{tabular}{|c|c|c|}
\hline Types & Codes defined as major attributes & Codes defined as minor attributes \\
\hline \multirow[t]{8}{*}{ Optimists } & Physical exercise & 'Not so bad' results \\
\hline & Preference for exercise and diet & Hygienic rules \\
\hline & & Weight loss \\
\hline & & Exercise and/or diet in progress \\
\hline & & Scheduled re-evaluation \\
\hline & & Patient's preference \\
\hline & & Recent changes \\
\hline & & Expectation \\
\hline \multirow[t]{7}{*}{ Negotiators } & Negotiation & Patient's promise \\
\hline & Hierarchical organisation & Adherence (drug or non-drug) \\
\hline & Limitation of instruction & Treatment interrupted \\
\hline & & Psychological profile \\
\hline & & Insulin \\
\hline & & Hopeless \\
\hline & & Circumstances of measurement \\
\hline \multirow[t]{6}{*}{ Checkers } & BP self-measurement & Unusual results \\
\hline & Scheduled re-evaluation & Referral \\
\hline & & Scheduled change \\
\hline & & Scheduled re-evaluation \\
\hline & & Borderline results \\
\hline & & Circumstances of measurement \\
\hline \multirow[t]{10}{*}{ Contextualisers } & Non-medical intercurrent event & Psychological profile \\
\hline & Intercurrent disease & Stress \\
\hline & Socioprofessional context & Familial context \\
\hline & & Adherence to treatment (drug or non-drug) \\
\hline & & Treatment interrupted \\
\hline & & Scheduled re-evaluation \\
\hline & & Alcohol \\
\hline & & Unusual results \\
\hline & & Other medical priorities \\
\hline & & Hierarchical organisation \\
\hline \multirow[t]{6}{*}{ Cautious } & Precautions of use & Drug-related intercurrent event \\
\hline & Adverse effects & Partial modification \\
\hline & & Minor modification \\
\hline & & Long prescription \\
\hline & & Maximal treatment \\
\hline & & Lifestyle changes first \\
\hline \multirow[t]{4}{*}{ Rounders } & Borderline results & 'Not so bad' results \\
\hline & & Unusual results \\
\hline & & Circumstances of measurement \\
\hline & & Scheduled re-evaluation \\
\hline \multirow[t]{2}{*}{ Scientists } & Other scientific reason & Doubt on treatment effectiveness \\
\hline & Other specialist's advice & BP self-measurement \\
\hline
\end{tabular}

striking. Diets of all kinds, physical exercise, weight loss and various other lifestyle modifications expected or prescribed were cited very often as reasons to delay a drug prescription. Although most guidelines do recommend lifestyle counselling as the first intervention, such a confidence in its effectiveness for high-risk patients with hypertension or type 2 diabetes is not supported by clinical evidence. ${ }^{33}$ Moreover, recent results suggest very little effect on clinical outcomes, if any, of lifestyle interventions in patients with diabetes. ${ }^{34}$ This confidence relates to the broader 'overestimation of care provided' issue, already described by Phillips et al as a cause of TI. ${ }^{15} 35$
Regarding the need to check BP, home or ambulatory BP measurement (HBPM or ABPM) is now the recommended procedure. $^{36} 37$ Taking into account HBPM or ABPM should therefore be regarded as appropriate, as long as it is not indefinitely repeated. In this study, very few physicians disregarded the results of such measurements. Nevertheless, a few 'checkers' did check values above targets up to five times for the same patient, without increasing the treatment over 2 years, which can hardly be justified. This also happened with LDL cholesterol and HbAlc values.

Negotiation is the core of the patient-centred shared decision-making. Negotiating the primary prevention of 
Figure 1 Study flow chart.

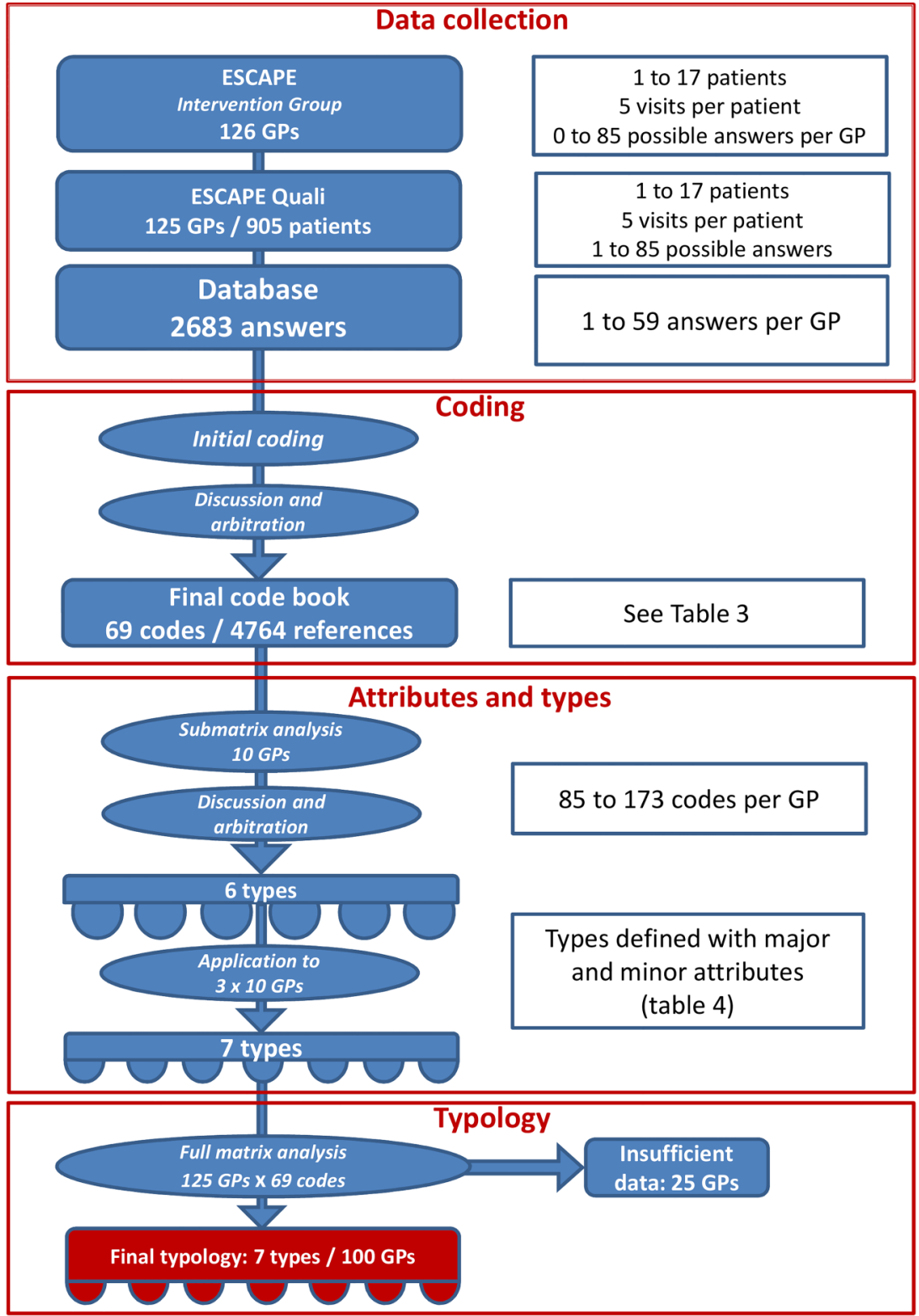

cardiovascular risk in a consultation raises some specific issues. $^{38}$ Cardiovascular risk prevention means lifestyle modifications and drug treatments for a benefit that remains hypothetical, and usually not discernible. Further, most patients will not agree with all the lifestyle or drug options available. This ambivalence relates to

Table 5 Inter-relations between the types

\begin{tabular}{|c|c|c|c|c|c|c|c|c|}
\hline & & \multicolumn{7}{|l|}{ Types } \\
\hline & & Optimists & Negotiators & Checkers & Contextualizers & Cautious & Rounders & Scientists \\
\hline \multirow[t]{9}{*}{ Tendencies } & Optimists & & $2(10 \%)$ & $2(13.3 \%)$ & $2(15 \%)$ & 0 & 0 & 0 \\
\hline & Negotiators & $3(10.7 \%)$ & & 0 & 0 & $1(9.1 \%)$ & $1(12.5 \%)$ & 0 \\
\hline & Checkers & $1(3.6 \%)$ & $2(10 \%)$ & & 0 & $1(9.1 \%)$ & $1(12.5 \%)$ & $1(20 \%)$ \\
\hline & Contextualizers & $1(3.6 \%)$ & 0 & $1(6.7 \%)$ & & 0 & $2(25 \%)$ & 0 \\
\hline & Cautious & 0 & 0 & 0 & $2(15 \%)$ & & $1(12.5 \%)$ & $1(20 \%)$ \\
\hline & Rounders & $1(3.6 \%)$ & $1(5 \%)$ & 0 & 0 & 0 & & 0 \\
\hline & Scientists & 0 & $1(5 \%)$ & 0 & 0 & $1(9.1 \%)$ & 0 & \\
\hline & None & $22(78.6 \%)$ & $14(70 \%)$ & $12(80 \%)$ & $9(69 \%)$ & $8(73 \%)$ & $3(37,5 \%)$ & $3(60 \%)$ \\
\hline & Total=92 & 28 & 20 & 15 & 13 & 11 & 8 & 5 \\
\hline
\end{tabular}

Twenty-seven GPs had a tendency-defined as one major attribute, and one or two minor-to relate to another type.

GPs, general practitioners. 
the controversy that arose when, in order to overcome clinical inertia, Phillips and Twombly suggested to 'run the numbers first and deal with blood pressure and glucose before asking about other problems' ${ }^{39}$ A number of researchers and physicians protested that such an attitude would oversimplify primary care and go against the principles of patient centredness. ${ }^{40}$ Elements of negotiation were present in a very large proportion of the GPs' responses gathered here, and most of them sounded relevant at first sight. However, GPs in the 'negotiators' group seemed to lead, with any given patient, the same negotiation about the same drug every 6 months for 2 years. In these cases, negotiating did not actually lead to any further action.

The 'rounding phenomenon' refers to three different behaviours, related to three possible reasons for inaction. The first one is the end-digit preference, or tendency of physicians to round down the results of measurement. ${ }^{41}$ For BP measurement, the results are usually rounded to the lower multiple 10 or 5 . Although the use of an electronic device reduces this tendency, it still exists and can significantly delay the initiation or reinforcement of a recommended treatment. ${ }^{41}{ }^{42}$ The second one is the 'close enough to target' issue, already extensively described. ${ }^{23} 3243$ It was mentioned here at least once by each of the 'rounders'. Although its consequences have not been as precisely assessed as with enddigit preference, it is likely to have the same effect. The third one is the 'mental adjustment' described by participants in the study by Howes $e t a l,{ }^{23}$ where physicians described how they mentally adjust down the BP actually measured to 'better represent the true BP' of the patient. Although such behaviour was not as clearly described here, it seemed to underlie the decision of some 'rounders'. Overall, rounding, in any of these three ways, might be a way to avoid a difficult or timeconsuming negotiation.

The context of the measurement provided a wide variety of reasons why the results were not regarded as reliable. At the time of the study, ambulatory measurements were not mandatory, and the three measurements made in the office were the standards for the study. Therefore, contextual reasons ranging from 'waited too long in the waiting-room' to 'didn't have enough time in the waiting room' are now outdated. Still, the 'contextualisers' paid much attention to any kind of stress that the patient was going through, regarding elevated $\mathrm{BP}$ as a consequence. This has probably much to do with a coincidence of words in French, where BP, muscular tension and psychological stress share the same denomination (tension). Supporting this hypothesis, the findings of Nicodème $e t a l^{44}$ in France, stressing the high impact of the 'immediate' context on the physician's decision of inaction, differ from those in English-speaking countries, where context refers more to the initial reason for consultation or to other medical priorities. ${ }^{23} 27$

Questioning the content of the guidelines is also a very common reason invoked by professionals for not following them. ${ }^{19}$ The usual criticism relates to their complexity, inapplicability in general practice and outdated evidence basis. ${ }^{19} 23$ This study did not find any rejection of the guidelines related to either their complexity or their inapplicability in daily practice. This unusual result may be due to the framework of the ESCAPE trial, where the GPs in the intervention group attended a 1-day training seminar about these guidelines and the way they should be followed. Therefore, the 'scientists' typology included GPs that criticised the validity of the guidelines on the basis of new scientific evidence. Indeed, during the 2 years of the study, two articles were published that concluded that low-dose aspirin for patients with hypertension and diabetes should be prescribed under certain conditions only. ${ }^{45} 46$ At the same time, a controversy arose about the maximum BP values that should be tolerated before initiating or increasing a treatment. A popular French evidence-based medicine journal advocated values above those defined in the guidelines. ${ }^{47}$ There were only five 'scientists' in our sample, but this should not be understood as a lack of scientific attitude in this GP population, since the typology related only to reasons for inaction.

\section{Strengths and limitations}

It should be noted that the names given to the types are actually nicknames referring to responses and not to the person, and therefore should not be considered as semantic description of the GPs included.

The GPs included were all investigators in the ESCAPE trial, and as such were recruited by the French National College of Teachers in General Practice. Many of them hosted a general practice trainee in their practice, and a substantial number of them were involved to various extents in teaching. Furthermore, they were all randomised in the intervention group of the trial and underwent a training seminar. Their involvement and motivation in treating cardiovascular risk factors was therefore different from the general population of GPs.

Results of LDL cholesterol, HbAlc and BP measurements were included in the Case Report Form (CRF), but the prescriptions were not, so it was not possible to know if a reason for not modifying therapeutics was given every time it should have been.

Two key points in the analysis process could introduce considerable subjectivity: initial coding and definition of the types. Modelling of the analysis by the researchers' assumptions is a bias nested in the core of qualitative analysis. We tried as much as possible to overcome this by blinded coding and analysis by separate teams of researchers. The initial coding and the types initially described separately by the two teams were remarkably consistent, although we had as little discussion as possible on the matter before the analysis.

Although many of the reasons given by the GPs for inaction were questionable, the analysis came across very 
few that could be regarded as definitely inacceptable, such as 'no time' or 'not in the mood'. One can imagine that in writing down the reasons for inaction, a physician would consider the acceptability of the response. This social desirability bias may have influenced the content of the data. Indeed, the typology defined here described the way GPs rationalised their decision of inaction, and thus may not elucidate underlying factors or motivations, especially those that might be considered socially unacceptable. Nevertheless, while it may not provide complete insight into the intimate mechanisms of inaction, it does provide a practical classification of justifications.

\section{Perspectives}

The answers given by the GPs were related to typical clinical inertia. ${ }^{15}$ Interventions so far have aimed at reducing inertia as a whole, but chances are that a proportion of the recorded inaction is actually appropriate patient-centred care. ${ }^{20}{ }^{40}$ This typology could help GPs elucidate their personal decision-making processes and help design physician-centred interventions aimed at reducing inappropriate inaction only.

Concerted and repeated efforts in implementing up-to-date guidelines have proven effective in addressing the recurrent issue of poor $\mathrm{BP}$ control but have still left room for improvement. ${ }^{48}$ Our results suggest that a welldefined set of doctor-related determinants are important. This reinforces the need for education and interventions aiming at the physician's behaviour.

More work is needed to understand the mechanisms of inaction in GPs' decision-making. First, the validity of this typology should be confirmed. One way could be to propose clinical case vignettes to these GPs, and check for the consistence of their declared behaviour with the attributes of the type they belong to. Second, a thorough exploration of their representations and inner feelings in these situations must be conducted.

\author{
Author affiliations \\ ${ }^{1}$ Department of General Practice, EES Research Team, University of Tours. \\ Faculté de Médecine, Tours, France \\ ${ }^{2}$ Department of General Practice, University of Tours. Faculté de Médecine, \\ Tours, France \\ ${ }^{3}$ Department of General Practice, University of Auvergne. Faculté de Médecine, \\ Clermont-Ferrand, France \\ ${ }^{4}$ Centre Hospitalier de Vendôme, Vendôme, France \\ ${ }^{5}$ Department of General Practice, REMES Research Team, University Paris \\ Diderot. 16 rue Henri Huchard, Paris, France \\ ${ }^{6}$ Department of General Practice, University Paris 13. UFR SMBH, Bobigny, \\ France \\ ${ }^{7}$ Department of Public Health, EES Research team University of Tours. Faculté \\ de Médecine, Tours, France \\ ${ }^{8}$ Department of Primary and Interdisciplinary Care, University of Antwerp. \\ Campus Drie Eiken, Antwerpen, Belgium
}

Acknowledgements The authors thank all the primary care physicians who participated in this study, which would not have been possible without their cooperation and strong commitment to the project. The authors also thank Carolyn Daher for reviewing the manuscript.
Contributors J-PL, J-SC, DP, VY, IA-A and AM designed the study and carried out the data collection and analysis. HV-R, ER, RR, EV and KH audited the whole methodological process. All authors contributed to the interpretation of findings and to the final construction of the typology. All authors contributed to the development of the manuscript. All authors had full access to all of the data in the study and can take responsibility for the integrity and accuracy of the analysis. The first author declares that the article is an honest, accurate and transparent account of the study.

Funding The study was an investigator-initiated one and was funded by unrestricted research grants from the French National College of Teachers in General Practice and Pierre Fabre Medicaments. The authors had full and sole responsibility for the study design, data collection, statistical analysis and interpretation of the data and for the writing of the report. The authors had complete independence over the design, integrity and publication of the study, without any intervention from the two partners.

Competing interests All authors have completed the Unified Competing Interest form (available upon request from the corresponding author) and declare that J-PL and DP have support from Pierre Fabre Medicaments for the submitted work; they have no relationships with companies that might have an interest in the submitted work in the previous 3 years; their spouses, partners or children have no financial relationships that may be relevant to the submitted work; and they have no non-financial interests that may be relevant to the submitted work.

Ethics approval Institutional Review Board of Versailles, France.

Provenance and peer review Not commissioned; externally peer reviewed.

Data sharing statement Extra data can be accessed via the Dryad data repository at http://datadryad.org/ with the doi:10.5061/dryad.c41b0.

Open Access This is an Open Access article distributed in accordance with the Creative Commons Attribution Non Commercial (CC BY-NC 4.0) license, which permits others to distribute, remix, adapt, build upon this work noncommercially, and license their derivative works on different terms, provided the original work is properly cited and the use is non-commercial. See: http:// creativecommons.org/licenses/by-nc/4.0/

\section{REFERENCES}

1. French National Authority for Health (HAS). Management of adults with essential hypertension. Paris: HAS, 2005. http://www.has-sante. $\mathrm{fr} /$ portail/jcms/c_272459/prise-en-charge-des-patients-adultesatteints-dhypertension-arterielle-essentielle-actualisation-2005cette-recommandation-est-suspendue

2. French National Authority for Health (HAS). Drug treatment of type 2 diabetes. Paris: HAS, 2006. http://www.has-sante.fr/portail/jcms/c_ 459270/traitement-medicamenteux-du-diabete-de-type-2recommandation-retiree-le-2-mai-2011

3. National Clinical Guideline Centre. Hypertension. Clinical management of primary hypertension in adults. London, UK: National Institute for Health and Clinical Excellence (NICE), 2011.

4. Mancia G, Laurent S, Agabiti-Rosei E, et al. Reappraisal of European guidelines on hypertension management: a European Society of Hypertension Task Force document. Blood Press 2009;18:308-47.

5. Staessen JA, Wang JG, Thijs L. Cardiovascular protection and blood pressure reduction: a meta-analysis. Lancet 2001;358:1305-15.

6. Boussageon R, Bejan-Angoulvant T, Saadatian-Elahi M, et al. Effect of intensive glucose lowering treatment on all cause mortality, cardiovascular death, and microvascular events in type 2 diabetes: meta-analysis of randomised controlled trials. BMJ 2011;343:d4169.

7. Briel M, Ferreira-Gonzalez I, You JJ, et al. Association between change in high density lipoprotein cholesterol and cardiovascular disease morbidity and mortality: systematic review and meta-regression analysis. BMJ 2009;338:b92.

8. Kearney PM, Whelton M, Reynolds K, et al. Worldwide prevalence of hypertension: a systematic review. J Hypertens 2004;22:11-19.

9. Joffres M, Falaschetti E, Gillespie C, et al. Hypertension prevalence, awareness, treatment and control in national surveys from England, the USA and Canada, and correlation with stroke and ischaemic heart disease mortality: a cross-sectional study. BMJ Open 2013;3: e003423. 
10. Godet-Mardirossian H, Girerd X, Vernay M, et al. Patterns of hypertension management in France (ENNS 2006-2007). Eur J Prev Cardiol 2012;19:213-20.

11. Wang YR, Alexander GC, Stafford RS. Outpatient hypertension treatment, treatment intensification, and control in Western Europe and the United States. Arch Intern Med 2007;167:141-7.

12. Grassi G, Cifkova R, Laurent S, et al. Blood pressure control and cardiovascular risk profile in hypertensive patients from central and eastern European countries: results of the BP-CARE study. Eur Heart J 2011;32:218-25.

13. Mounier-Vehier C, Amah G, Covillard J, et al. Management of essential arterial hypertension and cardiovascular risk levels. Observation in general medicine: national PHENOMEN study. Arch Mal Coeur Vaiss 2002;95:667-72.

14. Naderi SH, Bestwick JP, Wald DS. Adherence to drugs that prevent cardiovascular disease: meta-analysis on 376,162 patients. Am J Med 2012;125:882-7.

15. Phillips LS, Branch WT, Cook CB, et al. Clinical inertia. Ann Intern Med 2001;135:825-34.

16. Okonofua EC, Simpson KN, Jesri A, et al. Therapeutic inertia is an impediment to achieving the Healthy People 2010 blood pressure control goals. Hypertension 2006;47:345-51.

17. Andrade SE, Gurwitz JH, Field TS, et al. Hypertension management: the care gap between clinical guidelines and clinical practice. Am J Manag Care 2004;10:481-6.

18. Rodondi N, Peng T, Karter AJ, et al. Therapy modifications in response to poorly controlled hypertension, dyslipidemia, and diabetes mellitus. Ann Intern Med 2006;144:475-84.

19. Cabana M, Sand C, Powe N, et al. Why Don't physicians follow clinical practice guidelines? A framework for improvement. JAMA 1999;15:1458-65.

20. Lebeau JP, Cadwallader JS, Auger-Aubin I, et al. The concept and definition of therapeutic inertia in hypertension in primary care: a qualitative systematic review. BMC Fam Pract 2014;15:130.

21. Safford MM, Shewchuk R, Qu H, et al. Reasons for not intensifying medications: differentiating 'clinical inertia' from appropriate care. J Gen Intern Med 2007;22:1648-55.

22. Nwachuku CE, Bastien A, Cutler JA, et al. Management of high blood pressure in clinical practice: perceptible qualitative differences in approaches utilized by clinicians. J Clin Hypertens 2008;10:822-9.

23. Howes F, Hansen E, Williams D, et al. Barriers to diagnosing and managing hypertension-a qualitative study in Australian general practice. Aust Fam Physician 2010;39:511-16.

24. Hogan R, Blake R. John Holland's vocational typology and personality theory. $J$ Vocat Behav 1999;55:41-56.

25. Vitell SJ, Nwachukwu SL, Barnes JH. The effects of culture on ethical decision-making: an application of Hofstede's typology. In: Michalos AC, Poff DC, eds. Citation classics from the Journal of Business Ethics: celebrating the first thirty years of publication. New York: Springer Science and Business Media, 2013: $119-29$.

26. Kamhalová I, Halama P, Guráňková J. Affect regulation and decision making in health-care professionals: typology approach. Stud Psychol 2013;55:19-31.

27. Wackerbarth SB. The Alzheimer's family caregiver as decision maker: a typology of decision styles. J Appl Gerontol 2002;21:314-32.

28. Kluge S. Empirically grounded construction of types and typologies in qualitative social research. Forum: Qualitative Social Research, 2000. http://www.qualitative-research.net/index.php/fqs/article/view/ 1124

29. Patton MQ. Qualitative research and evaluation methods: integrating theory and practice. 4th edn. Thousand Oaks, CA: Sage, 2014.
30. Ayres L, Knafl KA. Typological analysis. In: Given LM, ed. The Sage encyclopedia of qualitative research methods. Thousand Oaks, CA: Sage, 2008:900-1.

31. Pouchain $D$, Lièvre $M$, Huas $D$, et al. EffectS of a multifaceted intervention on CArdiovascular risk factors in high-risk hyPErtensive patients: the ESCAPE trial, a pragmatic cluster randomized trial in general practice. Trials 2013;14:318.

32. Oliveria SA, Lapuerta P, McCarthy BD, et al. Physician-related barriers to the effective management of uncontrolled hypertension. Arch Intern Med 2002;162:413-20.

33. Lin JS, O'Connor EA, Evans CV, et al. Behavioral counseling to promote a healthy lifestyle for cardiovascular disease prevention in persons with cardiovascular risk factors: an updated systematic evidence review for the U.S. preventive services task force. Rockville, MD: Agency for Healthcare Research and Quality (US), 2014. http://www.ncbi.nlm.nih.gov/books/NBK241537/

34. Wing RR, Bolin P, Brancati FL, et al, for the Look AHEAD Research Group. Cardiovascular effects of intensive lifestyle intervention in type 2 diabetes. N Engl J Med 2013;369:145-54.

35. Davis D, Mazmanian P, Fordis M, et al. Accuracy of physician self-assessment compared with observed measures of competence: a systematic review. JAMA 2006;9:1094-102.

36. Parati G, Stergiou GS, Asmar R, et al, ESH Working Group on Blood Pressure Monitoring. European Society of Hypertension practice guidelines for home blood pressure monitoring. J Hum Hypertens 2010;24:779-85.

37. Blacher J, Halimi J-M, Hanon O, et al. Management of hypertension in adults: the 2013 French Society of Hypertension guidelines. Fundam Clin Pharmacol 2014;28:1-9.

38. Van der Weijden T, Bos LB, Koelewijn-van Loon MS. Primary care patients' recognition of their own risk for cardiovascular disease: implications for risk communication in practice. Curr Opin Cardio 2008;23:471-6.

39. Phillips LS, Twombly JG. It's time to overcome clinical inertia Ann Intern Med 2008;148:783-5.

40. Boyd CM, Vijan S, Sherrick RC, et al. Will running the numbers first violate the principles of patient-centered care? Ann Intern Med 2008;149:839-40; author reply:840-1.

41. Lebeau J-P, Pouchain D, Huas D, et al. ESCAPE-ancillary blood pressure measurement study: end-digit preference in blood pressure measurement within a cluster-randomized trial. Blood Press Monit 2011;16:74-9.

42. Nietert PJ, Wessell AM, Feifer $\mathrm{C}$, et al. Effect of terminal digit preference on blood pressure measurement and treatment in primary care. Am J Hypertens 2006;19:147-52.

43. Banegas JR, Lundelin K, de la Figuera M, et al. Physician perception of blood pressure control and treatment behavior in high-risk hypertensive patients: a cross-sectional study. PLOS ONE 2011;6:e24569.

44. Nicodème R, Albessard A, Amar J, et al. Poor blood pressure control in general practice: in search of explanations. Arch Cardiovasc Dis 2009;102:477-83.

45. Ogawa $\mathrm{H}$, Nakayama M, Morimoto T, et al. Low-dose aspirin for primary prevention of atherosclerosis events in patients with type 2 diabetes. A randomized controlled trial. JAMA 2008;300:2134-41.

46. Belch J, MacCuish A, Campbell I, et al. The prevention of progression of arterial disease and diabetes (POPADAD) trial: factorial randomised placebo controlled trial of aspirin and antioxidants in patients with diabetes and asymptomatic peripheral arterial disease. BMJ 2008;337:1840-50.

47. Prescrire Rédaction. [Hypertension artérielle, quels seuils et pour quoi faire?] Revue Prescrire 2006:26:843.

48. McAlister FA, Wilkins $\mathrm{K}$, Joffres $\mathrm{M}$, et al. Changes in the rates of awareness, treatment and control of hypertension in Canada over the past two decades. CMAJ 2011;183:1007-13. 